\title{
Integration of Electronic Services in the Execution of Business Transactions
}

\author{
Rainer Alt ${ }^{1}$, Stefan Zbornik ${ }^{2}$ \\ 1 Institute of Information Management, University of St. Gallen \\ 2 iTRUST Solutions AG, Schwerzenbach/Zurich
}

\begin{abstract}
Although most enterprises are using the Internet for business purposes today, the execution of business transactions remains a challenge. Areas where electronic services have established themselves include eLogistics, ePayments, and eFulfillment. However, solutions which integrate physical, financial and information logistics are still in their infancy. Starting from a definition of the business requirements and a review of the current situation in eLogistics, eFulfillment and ePayments we identify the invoice document as integration basis and describe Electronic Bill Presentment and Payment services as one possible approach towards creating integrated services for transaction execution.
\end{abstract}

Keywords: Integrated Logistics, Settlement, Electronic Logistics (eLogistics), Electronic Fulfillment (eFulfillment), Electronic Payments (ePayments), Electronic Bill Presentment and Payment (EBPP)

\section{ELECTRONIC BUSINESS TRANSACTIONS}

\subsection{Impact of electronic business transactions}

Electronic commerce (eCommerce) has had a significant impact on business in recent years. Indeed, nearly all Fortune-500 companies have implemented commercial Web sites (Westland and Clark, 1999), but these vary considerably in their functionalities. In general, the Internet is being used to support sales activities rather than as a new sales channel which handles electronic transactions. In a 2001 Forrester survey, $86 \%$ of 39 analyzed B2B websites offered search and 46\% logistics functionalities (Homs et al.,

\footnotetext{
The original version of this chapter was revised: The copyright line was incorrect. This has been corrected. The Erratum to this chapter is available at DOI: 10.1007/978-0-387-35617-4_48 
2001). A survey among 590 Swiss B2B and B2C Web sites has shown that companies mainly focused on providing corporate information (92\%), eMail $(84 \%)$ and product information (68\%). Only $23 \%$ of the Web pages supported online ordering, $5 \%$ online payment and a mere $2 \%$ electronic order tracking functionalities (Hüsemann et al., 2001).

Companies which achieve to handle a large amount of their transactions electronically are well known in various industries: Easyjet has $90 \%$, Ryanair 84\%, Cisco 70\%, Dell 50\%, Virgin Express 25\%, and IBM 17\%. Already IBM reported cost savings of some USD 1 billion in 1999 (Sager, 2000). Dell's competitive advantage is largely due to the short lead times of only 15 hours (Rocks, 2000). However, most of these integrated transaction systems are proprietary, i.e. the business partners were individually connected. Due to the necessary investments they go beyond the scope of many companies which have been investing heavily in enterprise resource planning systems (ERP) in the last decade. Although ERP systems streamlined the execution of internal transactions, they have not been designed to handle transactions among companies (Newton, 2001). Systems for electronic data interchange (EDI) were mainly limited to high volume transactions among established business partners (Angeles, 2000).

A broad variety of Internet-based services (WebServices) has emerged in the past years to reduce paper-prone and manual processes in the execution of business transactions with external partners. Relevant WebServices are termed eFulfillment, eLogistics and ePayments. Using standardized Internet technology and standards the costs of integrating execution functionalities in B2B or B2C solutions decrease. Forrester expects that in $200444 \%$ of all companies execute their transactions electronically (Homs et al., 2001) and IDC forecasts that the market for B2B and B2C logistics services will grow from USD 12 billion (2001) to 72 billion in 2004 (Ravi and Piper, 2000).

In this paper we analyze the perspectives of electronic bill presentment and payment (EBPP) services for the integration of transaction processing. Building on established logistics terminology the first chapter characterizes the relevant services for transaction execution. In the second chapter current approaches in these areas will be described. Our analysis yields a picture where existing services focus primarily on either information, physical or financial logistics. To achieve comprehensive electronic support in transaction execution, companies need to integrate at least three different services today. Chapter four identifies EBPP as one possible approach towards creating comprehensive services for transaction execution. Various scenarios are discussed of how to expand EBPP services into integrated services. 


\subsection{Areas of electronic business transactions}

Interorganizational transaction processing comprises three main activities (Schmid and Lindemann, 1998; Wigand et al., 1997): Information and contracting activities include product selection, product comparison, and the formulation of a mutually binding contract. In the following we will focus on the execution processes that are subsequent to the conclusion of the contract. Also referred to as settlement, order fulfillment (Newton, 2001) or execution, traditional logistics terminology is suitable to structure the main subprocesses within the execution process (Christopher, 1998):

- Physical logistics encompasses the physical delivery of the products which includes the selection of the carrier, tracking the shipment in transit, and physical transportation itself. The use of Internet technologies to support these activities is referred to as eLogistics (Bayles, 2001).

- Financial logistics encompasses primarily the execution of payments using alternative payment instruments (e.g. cash, credit card, remittance). Electronic payment services, such as ePayment Orders, eCash, Internet Credit Cards, are referred to as ePayments (Laudon and Traver, 2001).

- Information logistics encompasses order processing, delivery notification, invoicing and warehouse management. Solutions for the management of the information flow between buyer and seller are referred to as eFulfillment (Bayles, 2001).
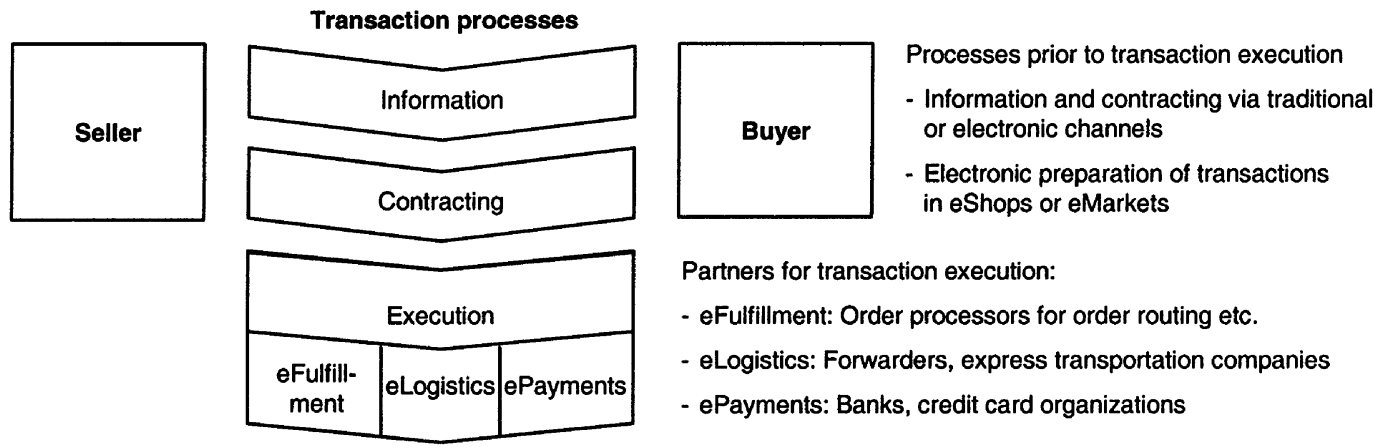

Figure 1: Focus of electronic transaction execution

\subsection{Emergence of transaction execution infrastructures}

One explanation for the slow evolution of electronic transaction execution may be the amount of costs involved which amount to at least $40 \%$ of the total costs of maintaining a Web presence (Bayles, 2001). What is in- 
volved is the integration of processing functions into the frontend and their integration with backend systems. While so-called adapters or cartridges with predefined interfaces are offered for the frontend area by providers of eBusiness software (e.g. SAP, Ariba), their integration with the backend systems is more or less company-specific and calls for a high degree of process reliability. Many companies regard these investments as an advanced stage in the development of their eBusiness solutions.

In analogy to other infrastructures (e.g. road transport, telecommunications), a whole industry is emerging around WebServices. These are currently discussed from two perspectives (Sleeper and Robins 2002): from a technological point of view WebServices enable connectivity among systems by providing XML-based standards such as ebXML, SOAP and WSDL $^{1}$. In the following we will focus on a business perspective which recognizes WebServices as standardized electronic services that can be used on a time-, transaction- or usage basis. Among the relevant WebServices are services for web access, directories, payments, portals, etc. Certain providers will undertake to preconfigure these WebServices and offer support in the form of collaboration infrastructures (Österle, 2001) or eInfrastructures (Sood et al., 1999). Various providers are preparing solutions in this area, e.g. EAI vendors (e.g. Webmethods, BEA), ERP vendors (e.g. SAP's Exchange Infrastructure) or CRM vendors (e.g. Siebel Universal Application Network). Other actors are eMarketplaces which are evolving from trading platforms to integration hubs for business transactions (Raisch, 2001).

\section{REQUIREMENTS AND EXISTING SOLUTIONS}

\subsection{General requirements}

At present, electronic transaction execution is largely based on the use of conventional solutions. There are, however, important differences between offline / conventional and online / electronic transaction processing (see Table 1). Typically, traditional logistics is not based on the assumption of small consignments that are the subject of anonymous, unplanned fine distribution, but, for instance, on supply chain management which presumes the precise definition and coordination of all actors in the logistic chain. eBusiness requires structures known from mail order businesses, e.g. own storage facilities with efficient fine distribution, call centers for customer service, as well 
as facilities for payments by credit card, cash on delivery, direct debits or bank remittances (Kuglin and Rosenbaum, 2001).

In an ideal system, there is no link on the customer's side to a execution service, i.e. a contact exists between the buyer and seller, and it is the latter who may employ suitable execution service providers. Alternatively, neither the buyer nor the seller employs an execution service and, instead, processing is done via an electronic marketplace or an execution infrastructure.

\begin{tabular}{|c|c|c|}
\hline & Offline/conventional execution & Online/electronic execution \\
\hline \multicolumn{3}{|l|}{ eLogistics } \\
\hline Type of shipment & Bulk goods & Piece goods \\
\hline Customer & Strategic & Unknown \\
\hline Destinations & Concentrated & Widely distributed \\
\hline \multicolumn{3}{|l|}{ eFulfillment } \\
\hline Order flow & Unidirectional & Bi-directional \\
\hline Demand & Stable, planned & Fragmented, unplanned \\
\hline Notification & None & Active / passive \\
\hline Order value $(\varnothing)$ & $>$ EUR 1,000 & $<$ EUR 100 \\
\hline \multicolumn{3}{|l|}{ ePayments } \\
\hline Instruments & $\begin{array}{l}\text { Materialized (cash, payment } \\
\text { slips, checks, plastic cards) }\end{array}$ & $\begin{array}{l}\text { Via networks (Internet, X.400, } \\
\text { Swift etc.) }\end{array}$ \\
\hline Presentation & Paper-based & $\begin{array}{l}\text { Electronic (HTML, PDF, EDI- } \\
\text { FACT, XML etc.) }\end{array}$ \\
\hline Payment & National & International \\
\hline Credit standing & Usually known & Often unknown \\
\hline Billing \& payment & Separate & Integrated \\
\hline
\end{tabular}

Table 1: Typical differences between offline and online execution

\subsection{Processes and actors in eFulfillment}

The starting point of eFulfillment is the electronic order entry, i.e. a decision has been made to buy a certain supplier's product (Hoover et al., 1996). The orders are passed on to the appropriate service providers or organizational units, their execution is monitored (order tracking), and eventually passed on to the billing department. In addition to these classical order processing functionalities, eFulfillment comprises warehousing activities, such as warehousing management, picking and packing, and restocking (Pyke et al., 2000). Related tasks have for some time been performed by classical logistics companies (e.g. Fiege, Kühne \& Nagel) with the aim to position themselves as logistic system providers (3PL). Since these services focus on a long-term logistic cooperation, they have no direct application to eBusiness. 
Examples for eFulfillment service providers are iShip, SubmitOrder and iFulfill.com in the US or inet-logistics in Europe. ${ }^{2}$ Ifullfill operates in-house warehousing and order picking services and charges a $7 \%$ credit card fee as well as a transaction fee of USD 1-4. The main requirements for eFulfillment are easy integration into websites, high-level customer service, and real-time links to all relevant carriers.

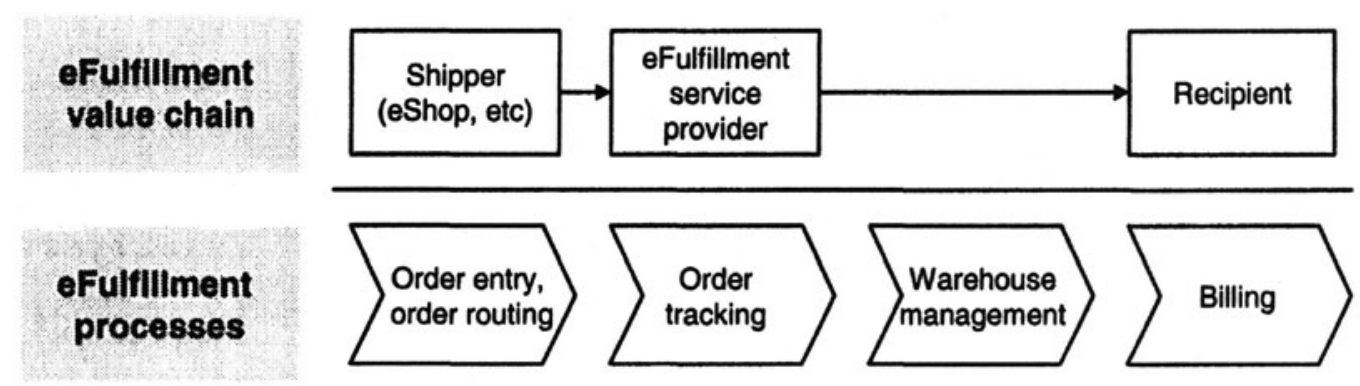

Figure 2: Actors and processes in eFulfillment

\subsection{Processes and actors in eLogistics}

The term eLogistics denotes the classical logistic functions, i.e. all activities around the so-called TTS processes (transport, transshipment, storage). There are four task areas that can be identified under the heading of eLogistics (Alt and Schmid, 2000):

- Selection / Organization. Consolidating logistic services for the handling of goods is the classical task undertaken by shipping agents. In the Internet arena it is rather operators outside the shipping industry or start-up enterprises that provide transport catalogs or transport exchanges. Examples include cargoweb.nl, loglink.net or teleroute.com.

- Tracking \& Tracing. Nearly all carriers today provide systems to determine the shipping status in real time. Usually, this can be accessed by entering the number of the bill of lading / waybill on the carrier's Web site.

- Documentation. Classical uses of EDI systems include the electronic generation of shipping documents. Forwarders will issue electronic shipping orders which are passed on by the shipping agents electronically to connecting carriers / correspondent forwarders, customs clearance agents, etc.

- Process management. Comprehensive or integrated physical logistic services (Leenders and Fearon, 1997) are today provided mainly by the so-

2 For an overview on eFulfillment services see http://www.digitrends.net/efulfillment 
called integrators (Fedex, UPS, DHL etc.). Their effectiveness resides in their ability to coordinate all physical activities due to vertical integration.

The main requirements for an eLogistics solution are multi-modality, internationality, and quality / reliability of physical transportation.

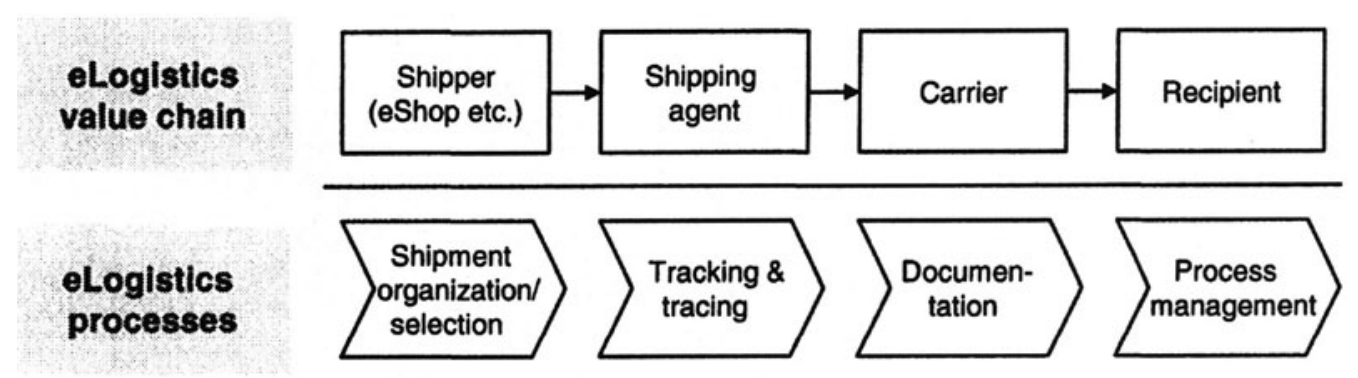

Figure 3: Actors and processes in eLogistics

\subsection{Processes and actors in ePayments}

In the financial logistics area, seller and buyer maintain a stable relationship with a principal bank and, generally, with one or two other banks. Transaction execution comprises activities between the payee (issuer of the bill), the payer (recipient of the bill), banks and the clearing organization. Compared to conventional payments which cost between USD 3 and 6, an electronic payment may be effected for as little as USD 0.20 (Westland and Clark, 1999). Europe has been leading in rationalizing payment transactions. Examples are the electronic payments order transfer (DTA), the electronic direct debiting service (LSV), the Electronic Funds Transfer at Point of Sale (EFT/POS) and Financial EDI (FEDI) (Barling and Jeffcoate, 1999):

- Electronic payments. Services to remit money are provided by banks, post offices and various specialized providers. Examples are GZS, SIZ or Postbank in Germany, Telekurs or Postfinance in Switzerland, APACS in the UK, and FDC/FDR in the US. Alternative solutions are provided in some market niches, e.g. purchasing cards by Visa. Established solutions have been around for 15 to 20 years and represent national solutions which differ in formats, security, etc.

- Documentation. Common services provided by banks typically include the furnishing of credit/debit advices and statements of account to their customers. This area is only rarely integrated on the customer's side. 
- Process management. Contrary to eFulfillment or eLogistics, an actor which integrates processes is missing in ePayments. A very promising approach is EBPP where bill presentment and payment are integrated.

An ePayments solution needs to meet four major requirements: multibank capability, cross-border payments, universal applicability for B2B and B2C payments and the support of various payment instruments.

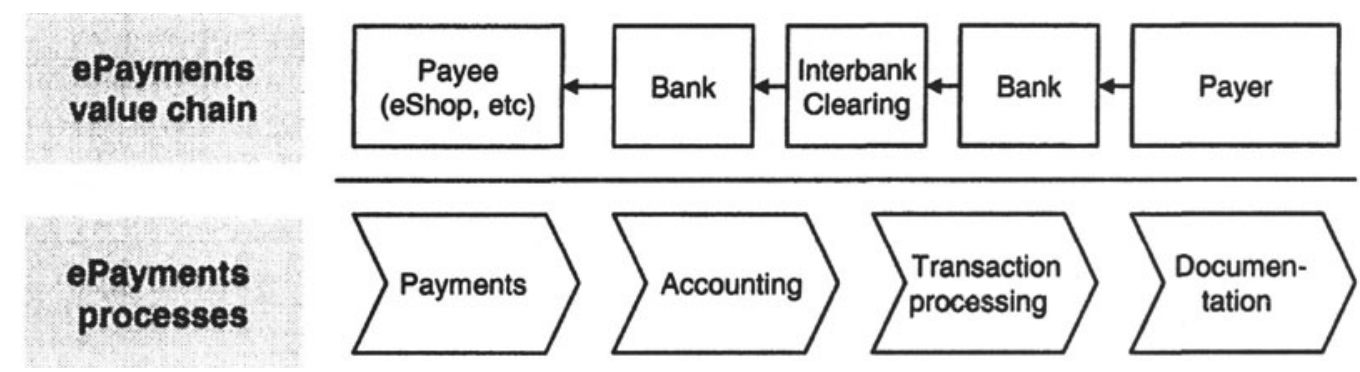

Figure 4: Actors and processes in ePayments

\section{ELECTRONIC BILL PRESENTMENT \& PAY- MENT AS A POSSIBLE NUCLEUS}

Existing WebServices are restricted to one logistics process (eFulfillment, eLogistics or ePayments) or even to segments (e.g. micropayments in ePayments or freight exchanges in eLogistics). Attempts to integrate physical, financial and information logistics (e.g. Eurolog, Encompass) have failed due to their complexity, missing standards, and political conflicts (Hoffmann et al., 1999). While integrated concepts do exist with integrators and postal services in eLogistics, there are no comparable services in financial logistics. Building on EBPP concepts, new options are emerging which will be discussed in the following.

\subsection{Models of Electronic Bill Presentment \& Payment}

Since the late nineties, EBPP has driven the development of concepts and systems for bills transmission and receipt as well as integrated payments. Operative systems in this field include, for example, PayNet, Checkfree, Spectrum, CyberBills, Paytrust, Billingzone, Clear Money, Paymybills, eBX e-Biller, PayBill, Seals, etc. A rapidly growing market with significant profit potentials is forecasted (Barling and Jeffcoate, 1999): By 2005, more than 30 billions of bills are expected to be electronically processed, the fee charged 
per transaction being assumed to amount to anything up to 1 US Dollar. The markets for EBPP services in the USA and notably in Europe are still in their early stages of development (Newcomb et al., 1999). So far, two basic models have emerged for EBPP (Ouren et al., 1998; NACHA, 1999):

- Biller Direct. The issuer of the bill presents bills to customers direct by means of eMail, WWW, or EDI. This may be done through the issuer's own infrastructures or a specialized service provider. The main problem is that the recipient of the bill (payee) may receive many different bills via different channels and in different data formats from their suppliers.

- Consolidator. To overcome the biller direct problem a consolidator collates the bills from different sources to present them in a digestible format via the Web, EDI, E-Mail, etc. to the recipients. In the case of a:

- Thick consolidator, billers transmit all information to the consolidator to be passed on to the customer.

- Thin consolidator, the bills transmitted to the consolidator only include a summary of the relevant payments. Other details are presented by billers on their own portal.

While the B2B area prefers the biller direct and the thick consolidator model, the B2C area is currently rather for the thin consolidator model.

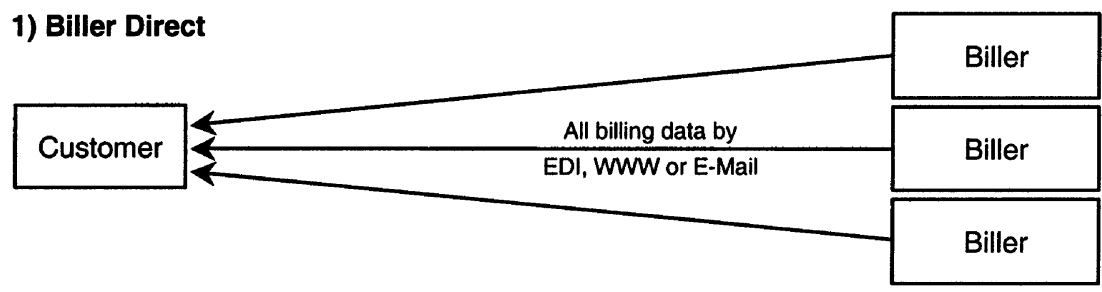

2) Thick Consolidator

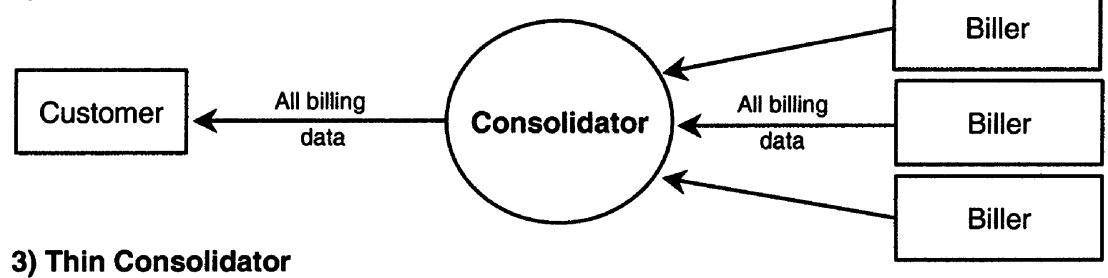

3) Thin Consolidator

Billing details

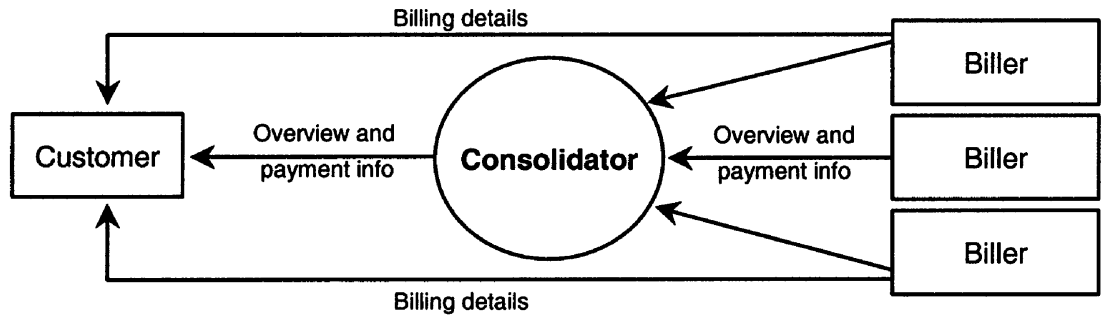

Figure 5: Models of Electronic Bill Presentment \& Payment 


\subsection{Examples of Electronic Bill Presentment \& Payment}

At present, the market for EBPP systems is still dominated by US companies. Although these systems are aimed at replacing the use of checks as the prevailing method of money transfer in the US (approx. 70\% market share; BIS, 2001), they show the main functional categories of EBPP (NACHA, 1999):

- Biller Service Providers (BSPs) support the biller in the electronic preparation and presentation of bills. This area is covered by well-established firms in the print, mail and letter-shop business, e.g. Pitney-Bowes.

- Biller Payments Providers (BPPs) support the biller in collecting outstanding receivables. Examples are banks and factoring companies in Europe and lock-box providers in the US.

- Customer Service Providers (CSPs) use portals for the presentation of bills to customers (private persons and SMEs). Financial institutions and major billers (e.g. Telcos,) are trying to enter this new area.

- Customer Payments Providers (CPPs) handle the payment of bills for their customers. Actors are banks, credit card companies, payment service, postal banks, and, also mobile communication companies.

- Consolidator Services coordinate the electronic exchange of bills between customers and suppliers and offer additional services. They are important where the firms involved use different CSPs and BSPs.

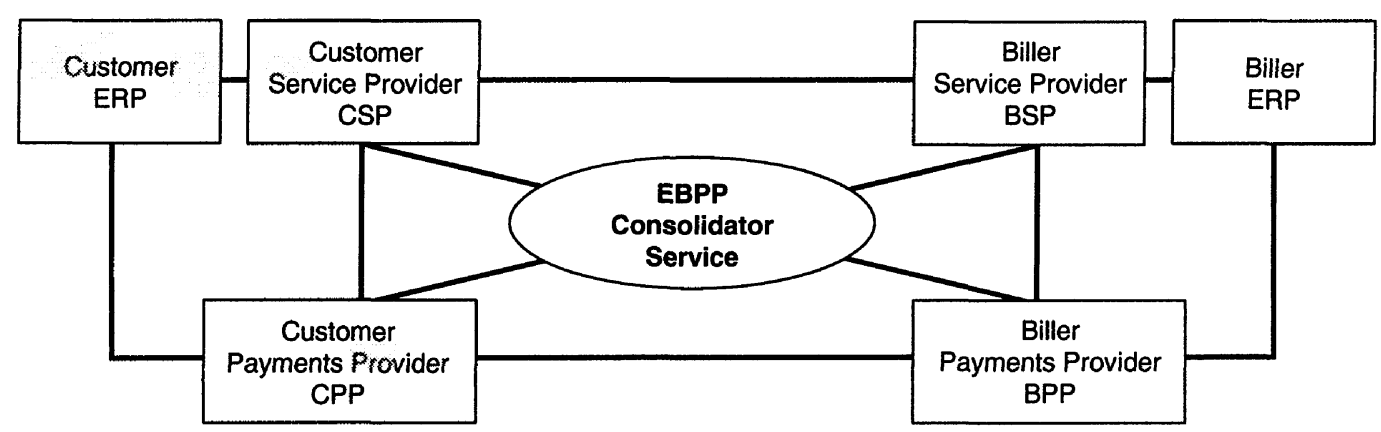

Figure 6: Functional Service Components in Electronic Bill Presentment \& Payment

In addition, the ERP systems which are used by customers and billers increasingly include EBPP functionalities which make integration to an EBPP service easier. An example is SAP which bought Swiss Telekurs' EBPP software PayNet in December 2001. The system is now being integrated in the mySAP Financials solution (Scheuermann, 2001). 


\subsection{IT-Architecture of EBPP Services}

Due to their consolidator function EBPP services have a typical hub-andspoke architecture (see Fig. 6) which is a suitable topology for the integration of eFulfillment, eLogistics, and ePayments services. From a technological perspective EBPP services have two main functionalities (see Fig. 7):

- Internal functionalities. EBPP services require functionalities for the direct business (clearing systems, transaction and historical data bases, user interfaces, etc.), supporting functionalities (partner directories, filing systems, converters, etc.), as well as infrastructure components (Web servers, communication systems, firewalls, etc.).

- External interfaces. As n:m platforms EBPP services support the workflow between several partners. These include billers and bill recipients, external services of financial logistics (banks, credit card organizations, PKI certification authorities, clearing organizations) as well as other complementary services (partner directories, online shops, etc.).

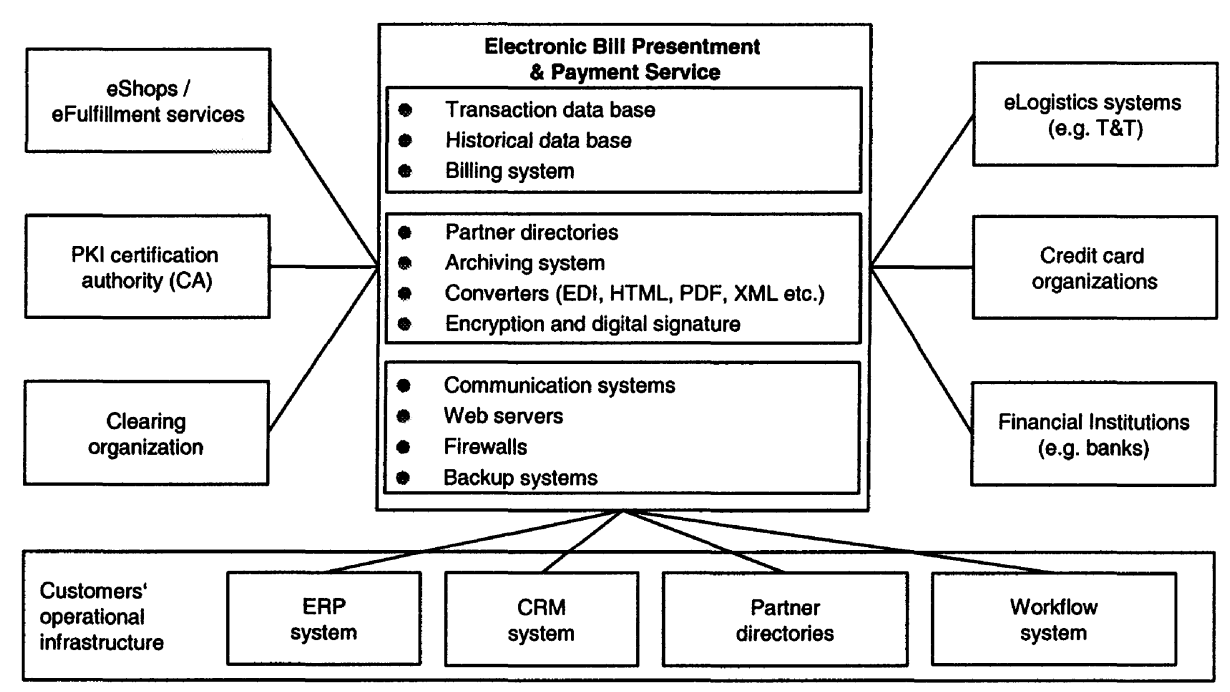

Figure 7: IT-architecture of an EBPP service 


\section{INTEGRATED TRANSACTION EXECUTION WITH EBPP}

\subsection{Integration of eLogistics and eFulfillment}

The potentials of EBPP systems to form the nucleus of an integration reside in the topology of EBPP systems and the central role of the invoice (see Fig. 8). The invoice document (bill) contains both information from eFulfillment and eLogistics (delivery dates, recipients of goods, items to be delivered, shipping arrangements, etc.) as well as information for ePayments (bank and account information, amount to be paid, terms of payment, etc.). There are three integration scenarios that can be identified for EBPP:

- The bill is generated upon the receipt of the order and is transmitted and presented electronically to the customer. The latter checks the bill and releases it for payment which is notified to the seller by means of status information. Only then are the goods released for dispatch. An example is the booking of flight tickets with a travel agency or with the airline.

- The bill is generated electronically by the supplier and transmitted directly or via a consolidator to the customer. At the customer's end, the bill can be entered directly into the ERP system. This would, for instance, allow extensive automation of the tedious checking of items received against items billed and simplify allocation to accounts.

- EBPP and eFulfillment/eLogistics services form a logic complement to online shops and electronic marketplaces. In future, it will be those shops and marketplaces that provide optimized and simple integration of the processing services. Electronic orders should be executed by 'the click of a button' or even automatically. 


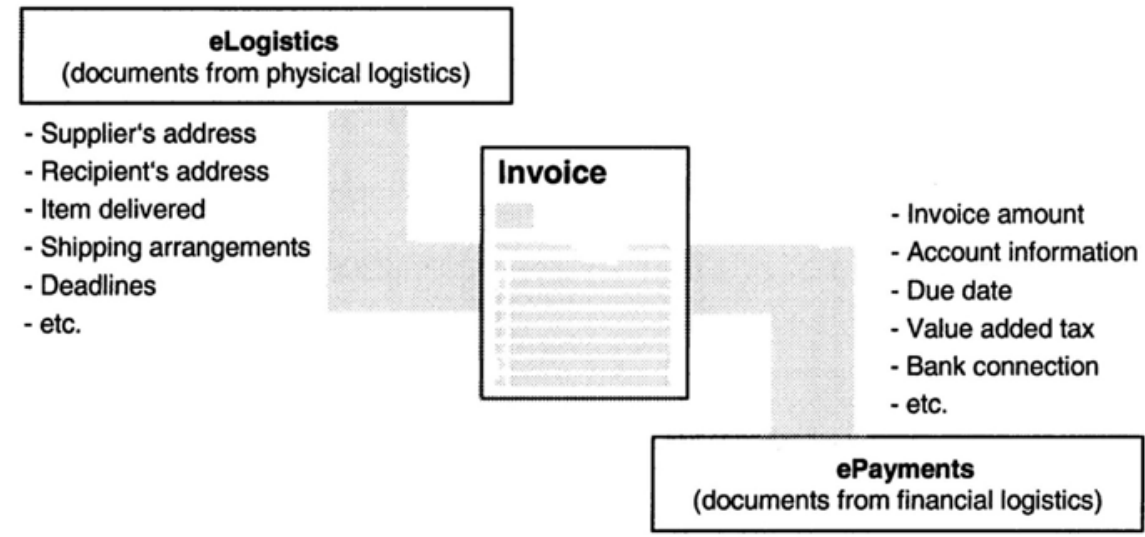

Figure 8: Integration of physical and financial logistics via invoice document

\subsection{Cooperation between service providers}

In addition to streamlining the management of the total process, linking up of the individual processing areas opens up additional business opportunities for many companies. In respect of EBPP and the future coverage of the different market sectors, a key question for the service providers at present is about who will occupy the interface with the customers in future (Van Dyke, 2000): Will it be the banks with their financial portals, the consolidators with their multi-bank-capability portals, providers of universal portals, like Netscape, or large billers, like Telecoms, with their own portals?

- Banks. To defend their established core competences banks look upon EBPP as a new instrument to 'loyalize' their customers through providing them with an instrument that may be integrated into their own portals. $^{3}$

- Telecoms and Internet Service Providers (ISP). EBPP is used by both Telecoms and ISPs in their portals for the billing of their own customers. The solutions now being offered on the market mark a logic development. $^{4}$

- Non-Banks. IT-companies such as Microsoft, FDC, Oracle, IBM, Netscape or Sun are recognizing the EBPP market as a technical challenge and are trying to make inroads into the value chain of banks. ${ }^{5}$

- Postal services. At present, the delivery of paper mail still forms the major business segment of postal services. In view of a decreasing tradi-

3 See e.g. e-Billing by Citibank (http://www.citibank.com/e-business/homepage/ebilling)

4 See e.g. eRechnung by Swisscom (http://www.swisscom-fixnet.ch/erechnung)

5 See e.g. BillerXpert by Sun (http://wwws.sun.com/software/products/billerxpert) 
tional business, postal services are developing and launching EBPP solutions. $^{6}$

\section{CONCLUSIONS}

Electronic transaction execution involves the integration of multiple service providers from different industries. Existing electronic services have limited application - not least due to their historical roots - to only a few areas. In the areas of eLogistics and eFulfillment, there are a number of companies which have for quite some time been trying to standardize the workflow between the partners in physical logistics and to achieve higher levels of integration. A reasonable measure of success has only been attained by integrators and postal services due to atomistic market structures and high process complexities. However these solutions are lacking the functionalities of ePayments.

In the payments arena, Electronic Bill Presentment and Payment (EBPP) is the first service that has significant integration potential to eFulfillment and eLogistics. This new aspect of EBPP recognizes the invoice document (bill) as the container of all relevant transaction information. To date the adoption of EBPP services has not lived up to the expectations which were forecasted two years ago. One success factor besides improvements regarding security concepts, legal frameworks or international standards is increased business value via integrated processes. Integration of transaction processes is key to most interorganizational strategies, such as virtual or real-time organizations.

Various actors are currently trying to establish a foothold in the European EBPP market. For integrated services the primary interest of EBPP service providers will be in seeking cooperation with providers of integrated logistics services. An example is the cooperation of Cybersource and former Ordertrust. Apart from that, efforts will be made by eFulfillment and eLogistics service providers to go beyond credit card payments and promote their own EBPP solutions. Which solution will create the future standard cannot be answered today. We assume that there will be a few dominating EBPP consolidator services and a host of complementary EBPP services establishing themselves in Europe in the long term. 


\section{REFERENCES}

Alt R, Schmid B (2000) Electronic Commerce und Logistik - Perspektiven durch zwei sich wechselseitig ergänzende Konzepte. In: Zeitschrift für Betriebswirtschaft, 70 (2000) 1, 7599

Angeles R (2000) Revisiting the Role of Internet-EDI in the Current Electronic Commerce Scene. In: Logistics Information Management 13 (2000), 45-57

Barling B, Jeffcoate J (1999) Electronic Bill Presentment and Payment - Creating Opportunity from Necessity. Ovum, London

Bayles DL (2001) E-Commerce Logistics \& Fulfillment: Delivering the Goods. Prentice Hall, Upper Saddle River (NJ)

BIS (2001) Statistics on Payments Systems in the Group of ten Countries - Figures for 1999. Bank for International Settlements, Basel

Christopher M (1998) Logistics and Supply Chain Management: Strategies for Reducing Cost and Improving Service. $2^{\text {nd }}$ ed., Financial Times, London etc.

Hoffmann CP, Gerbode A, Hunziker A, Klose M, Pötzl J (1999) Logistics and Electronic Commerce - Potentiale für einen Logistics Service Provider im Bereich der Business Media. Project Report LogEC II, University of St. Gallen

Homs C, Meringer J, Grammatico L, Rehkopf F (2001) ROI of Europe`s B2B Commerce Sites. Forrester Research, Amsterdam

Hoover WE, Tyreman M, Westh J, Wollung L (1996) Order to Payment. In: The McKinsey Quarterly, (1996) 1, 38-49

Hüsemann S, Meier A, Wismer D, Meyer K, Wohlwender P (2001) Einsatz und Entwicklung von Electronic Business in Schweizer Unternehmen. In: Meier A (Ed.) Internet \& Electronic Business. Orell Füssli, Zurich, 41-57

Kuglin FA, Rosenbaum BA (2001) The Supply Chain Network @ Internet Speed. Amacom, New York etc.

Laudon KC, Traver CG (2001) E-Commerce: Business, Technology, Society. Addison Wesley, Boston (MA) etc.

Leenders MR, Fearon HE (1997) Purchasing and Supply Management. $11^{\text {th }}$ ed., Irwin McGraw-Hill, Boston (MA) etc.

NACHA (1999) An Overview of Electronic Bill Presentment and Payment Operating Models: Process, Roles, Communications, and Transaction Flows. NACHA Council for Electronic Billing and Payment, Herndon (VA)

Newton CJ (2001) Managing Order Fulfillment Across the Supply Chain. AMR Research, Boston (MA)

Newcomb B, Weisman DE, Doyle B, Macklin M, Kopikis K (1999) Bill Presentment's Late Delivery, Forrester Research, Cambridge (MA)

Ouren J, Singer M, Stephenson J, Weinberg AL (1998) Electronic Bill Payment and Presentment. In: The McKinsey Quarterly, (1998) 4, 98-106

Österle H (2001) Enterprise in the Information Age. In: Österle H, Fleisch E, Alt R (Eds.) Business Networking: Shaping Collaboration between Enterprises. 2nd ed., Springer, Berlin, etc., 17-53

Pyke DF, Johnson ME, Desmond P (2000) eFulfillment - It's Harder than it Looks! http://mba.tuck.dartmouth.edu/pages/faculty/dave.pyke/papers/efulfillment.pdf

Raisch WD (2001) The eMarketplace: Strategies for Success in B2B eCommerce. McGraw Hill, New York etc.

Ravi R, Piper T (2000) eLogistics: The Bedrock of Successful eCommerce - Market Overview, Forecast, and Analysis, 2000-2004. Report No. W23289, IDC, Framingham (MA) 
Rocks D (2000) Dell's Second Web Revolution. In: Business Week, Sept. 18, pp. EB42-EB45 Sager I (2000) Big Blue Gets Wired. In: Business Week, April 3, EB56-EB58

Scheuermann HD (2001) Empowering Finance for E-Business: Gaining Competitive Advantage through mySAP Financials. In: Proceedings mySAP Financials Conference, Basel

Schmid B, Lindemann M (1998) Elements of a Reference Model for Electronic Markets. In: Blanning RW, King DR (Eds.) Proceedings $31^{\text {st }}$ HICSS, Vol. IV, IEEE Press, Los Alamitos (CA), 193-201

Sleeper B, Robins B (2002) The Laws of Evolution: A Pragmatic Analysis of the Emerging Web Services Market. The Stencil Group, San Francisco (CA)

Sood R, Friedman J, Parekh M, Sherlund RG, Bahramipour L, Berquist T (1999) B2B: 2B or Not 2B? Goldman Sachs Investment Research, New York (NY) etc.

Van Dyke J (2000) Online Bill Presentment - Banks Must Ally to Defend Share as EBPP Market Opens. Jupiter Communications, New York

Westland JC, Clark THK (1999) Global Electronic Commerce: Theory and Case Studies. MIT Press, Cambridge (MA)

Wigand RT, Picot A, Reichwald R (1997) Information, Organization and Management. Wiley \& Sons, Chichester 